\title{
CREATIVITY IN SCIENCE DOMAINS: A REFLECTION
}

\author{
CREATIVIDAD EN LA CIENCIA: UNA REFLEXIÓN
}

\section{SORAIA GARCÊS*}

\begin{abstract}
Creativity is a key element for development and innovation in all areas of expertise domains. Years of misconceptions led to the belief that creativity is an ability only a few possess, particularly individuals from the arts. This assumption is far from the truth: we are all creative. We have different creative styles, but in all domains creativity takes part. Science is one of the richest fields where we can find it. This paper brings a reflection upon creativity in science, defining it, drawing similarities between the creative process and the scientific method, while arguing the importance of recognising creativity as a fundamental piece of past, present, and future scientific discoveries; but also in everyday scientific achievements.
\end{abstract}

Keywords: Creativity, science, creative process, scientific method, scientific creativity.

\section{RESUMEN}

La creatividad es un elemento clave para el desarrollo y la innovación en todos los ámbitos. Años de conceptos erróneos llevó a la creencia de que la creatividad es una habilidad que sólo algunos poseen, en particular los artistas. Sin embargo esta suposición está lejos de la realidad: todos somos creativos. Tenemos diferentes estilos, pero en todos los ámbitos participa la creatividad. La ciencia es uno de los campos más ricos donde la encontramos. Este artículo aporta una reflexión sobre la creatividad en la ciencia, definiéndola, trazando semejanzas entre el proceso creativo y el método científico, mientras argumenta la importancia de reconocer la creatividad como pieza

* PhD in Educational Psychology, researcher in the Centro de Investigação em Estudos Regionais e Locais da Universidade da Madeira (CIERL-UMa), Funchal, Portugal. Correo electrónico: soraiagarces@gmail.com 
fundamental en los descubrimientos científicos del pasado, presente y futuro, como también en los logros científicos cotidianos.

Palabras clave: Creatividad, ciencia, proceso creativo, método científico, creatividad científica.

Recibido: 10.05.17. Aceptado: 31.08.17.

\title{
INTRODUCTION
}

\begin{abstract}
Reativity iT's a concept that has seen in the last few years a burst of interest by the scientific community; but still lacks a full understanding. One of the focus points of many scholars has been if creativity is an ability that all of us possess, despite our field of knowledge or studies (Baer, 2012; Feist, 1998; Ivcevic, 2007; Mumford et al., 2010; Perrine and Brodersen, 2005; Reid and Petocz, 2004; Charyton and Snelbecker, 2007). Being many times associated only with the arts and the artists, science and scientists have been neglected as a domain and a field where we can find enormous amounts of creativity and creative products. This paper aims to explore this idea of creativity in science; destroying the myth that creativity lives only in the arts; reflecting of its importance for science domains and; in this way, unveil creativity in science.
\end{abstract}

\section{CREATIVITY AND CREATIVE STYLES}

Creativity is a topic in high demand nowadays, particularly in workplaces. Today it's not enough to have only a good knowledge background; abilities such as creativity are fundamental to innovate, to adapt and to go beyond the boundaries of the conventional. Economic crisis have ignite a boom of creative ideas as a way to survive. The absence of jobs, the need to think of new ways to earn money has, in this sense, a positive side: people inner creativity capabilities are brought to the surface. However, a proper and universally accepted definition of creativity is still elusive. Many give their interpretations of the concept, but a consensus among the scientific community has its ups and downs. Disagreeing with this idea, Feist (1998) argues that researchers have already achieved an unanimous definition of creativity, when it is said that creativity must be express in an original and 
adaptive way; this means that two major points are agreed by researchers: the manifestation of creativity must contain, simultaneously, novelty and usefulness on any field (Aldous, 2007). One of the best definitions of creativity, in my opinion, is presented us by Torrance (1965) when he stated that creativity is mainly a process; a process that allows us to be more attentive to problems, lack of elements or "blind" spots in knowledge; find those difficulties and therefore develop solutions, assumptions or hypotheses; test and retest them; change and retest them again and; communicate the outcomes. This definition, given us by Torrance (1965) allows us to acknowledge a large set of important elements,

It enables us to begin defining operationally the kinds of abilities, mental functioning and personality characteristics that facilitate or inhibit the process. It provides an approach for specifying the kinds of products that result from the process, the kinds of persons who can engage most successfully in the process, and the conditions that facilitate the process. The definition also seems to be in harmony with historical usage and equally applicable in scientific, literary, dramatic, and interpersonal creativity.

Guilford (1950) in his APA speech proclaimed the need to further study creativity and today, I believe, we can see progresses in the scientific world: scientific journals specialized in creativity, in numerous books and lectures given to promote it and policy strategies that acknowledge the need for creativity. We may not be where Guilford thought we should be, but we're making a path that is gradually increasing its contribute to the world of creativity and ultimately exploring the human being capabilities. Thus it is important to recognize its significance in all domains of study. The first approaches to creativity associated it to mystical powers and to the whimsical artist, the one that the gods granted the inspiration to create; later on these same artists were considered mad people (Dacey, 1999; Wechsler, 2008). These initially views of creativity don't help to acknowledge creativity in a scientific manner; and these ideas are still embedded in the minds of countless people, despite the growing concern by the scientific community to give it a legit place in science. More, this cultured printed ideas still lingering in people minds make some believe that only the "chosen ones" are capable of being creative. In this regard, Gomes (2007) stated that everyone has creative skills, however some have a little more than others. These differences between people, may have a genetic component but it is largely because of the failure to people express their full creative potential (Gomes, 2007). 
My view is that creativity is in everyone and for everyone. Creativity is not something exclusive of one field of studies; each and everyone one of us, regardless of the education received, has it; but we use it in different ways. We all have different styles on how we create and how we put ideas into practice; but we vary in our way of expressing our own creativity. Thus many have been acknowledging and studying the existence of different creative styles. Kirton (1976) presented the adaptors and the innovators that are located in the extremes of a continuum that moves from the capability to do better, to the capability to do differently. Selby et al. (2004) developed VIEW to assess problem-solving styles; they identified three dimensions: a) Orientation to Change, (b) Processing and; (c) Deciding; but stated that "No single score or set of scores is more or less socially valued than any other, and no approach is more (or less) creative than others". Wechsler (2006, 2007) talked about the creating and thinking styles, defining the creative styles as the preferred manner in which each one of us think and express our own creativity. Nogueira et al. (2015) analyzing the factorial structure of the Portuguese version of the Creating and Thinking Styles Scale developed originally by Wechsler (2006), and initially adapt to Portuguese in previous studies (Garcês, 2011; Garcês and Pocinho, 2011; Ibérico Nogueira et al., 2012; Garcês et al., 2014), concluded with a three-factor model structure called Troika Model. This structure showed the existence of three creative and thinking styles, namely Non-Conforming/Transformer, Cautious/Reflexive and Logical/Objective, where the logical/objective deemed more a thinking style and the other two creating styles "suggesting the possibility of a 2-axis model in which one axis corresponds to a continuum between the Cautious/Reflexive and the Non-Conforming/Transformer styles and the other axis corresponds to the presence of the Logical/Objective styles" (Nogueira et al., 2015). This modeling of concepts is once again shedding light that creativity can be expressed in many different ways, which means there is not only one way to be creative and each one of us can be creative in their own right and in their own environment including science.

Basadur et al. (2014) argued that the creative problem-solving process has four cyclical stages: (a) generation, (b) conceptualization, (c) optimization and (d) implementation, that reflect the need for different cognitive activities or abilities in each one of them; hence the authors acknowledge that we all have different preferences regarding each step of the process, leading us to have diverse creative problem-solving process styles.

Understanding the existence of creative styles puts in perspective pre- 
conceived notions that creativity is only for artists, for those who are "born" with the ability to be an extraordinary singer or a tremendous painter; but that could not be more far from the reality: creativity is a cornerstone for science and for scientific works, as it is fundamental for innovation and for the success of research and development of organizations and culture (Burbiel, 2009). We all have potential for creativity, we may simply use it in a more or less efficient and/or in different ways than others do.

\section{CREATIVE PROCESS AND SCIENTIFIC METHOD}

When defining creativity the perspectives of researchers frequently vary accordingly to their study interests. Torrance (1965), as already stated, was one of the most famous and greatest contributors to the study of creativity. In his conceptualization of creativity Torrance gave us one of the richest interpretation of the creative process. Highlighting the creative process gives us a better understanding that creativity is not instantaneous; there is a set of underlying and interconnected stages. Accordingly, DeHaan (2009) stated that creativity is a process and not simply an individual event; there is an interaction of several cognitive and affective variables. When someone experiences an eureka moment it is probably the outcome of a complex process where group and social interactions may have had some influence; this process, despite appearing instantaneous, most likely included three major components: (a) divergent thinking skills; (b) convergent thinking abilities and; (c) analogical thinking (DeHaan, 2009). The creative process clearly involves abilities such as fluency and cognitive flexibility; however high degrees of these and other abilities involved in this process does not imply a guarantee of creative results; though it allows a higher potential to behave in a creative way (Torrance, 1965). For Burbiel (2009) the creative act has two stages: (a) the idea generation and (b) the idea validation. The first one implies divergent thinking skills and the second convergent thinking abilities are required. Validation is fundamental for scientific environments, since just a few ideas can come to reality. Wallas (1926) was one of the first, if not the first, to address the issue of the creative process and to give the scientific community a first structure: (a) preparation; (b) incubation; (c) illumination and; (d) verification. In the first stage a problem is encountered, information is sought out and the problem is investigated; in the incubation stage the unconscious processes are the primarily workers, it 
is a step of indirect work, where the person does not actively seeks to solve the problem, is a step where information is "floating" in the unconscious and playing combinations; the third stage, the illumination is markedly known as the insight stage, it is a moment where a solution comes to the mind, where all previous work come to fruition and a mental leap takes place; the last stage regards verification; here the solution is more truly evaluated and refine, the idea polished and a conscious effort takes place to improve it and then present it to the public.

Looking at the creative process we can draw some similarities with the scientific method. Nichols and Stephens (2013) stated that this method also has a set of steps. The first one - problem definition - where a problem emerges and needs a response, which entails a search and gathering of information, that leads to the second step - hypothesis building - where a possible solution is achieved and then observed and tested - experimentation and observation - follow by a - results analysis and conclusion formulation - that leads to - results communication - and - feedback - gathering, which can in turn lead to a new full cycle of information searches, hypothesis construction, experimentation, analysis, communication and feedback.

Highlighting the scientific method brings a close look to a full set of methodologies that involves science. These steps are many times interrelated, being difficult to drawn the line, when one starts and the other ends. The same can be said about the creative process; there is a thin line between the steps, which makes a clear distinction between the different stages challenging. But this is not the main point of confluence regarding the creative process and the scientific method, in my opinion; having showed the main basic steps of conceptualization in both methodologies, we can clearly see resemblances amongst the two. First, both address a problem or a question that needs to be resolved; the two formulate hypothesis or ideas on how to approach the problem; both experiment or test their ideas and/or hypothesis, analyze results and show them to the public to receive feedback; and also the two can be described as cyclic (Nichols and Stephens, 2013). But foremost, both are described as processes; creativity is not instantaneous, nor is science; both involve much more than simply putting an idea in the spotlight, both involve hard work that can sometimes be overshadowed by the results, but nevertheless exists and takes place in prior stages before a final product is available to the public.

Burbiel (2009) acknowledged an important aspect that cannot be left unspoken: research and development is largely taken care by project groups. The majority of creative works occurs in organizational settings 
with teams, making it a social process. From the interaction between different minds the bulk of scientific and artistic works emerge. Idea generation is better when developed in groups, being that the interaction between people promotes creativity (Burbiel, 2009). The most influential scientists are very creative; but "although creativity can be partially explained by internal psychology, we can explain more about scientific creativity by also examining broader social patterns" (Sawyer, 2006). Science has in collaboration its higher activity outlet, being from these collaborative works that creative ideas emerge. The best scientists recognize that scientific creativity is helpless without others, so they embrace collaborations with others, acknowledging that for scientific progress a group effort is needed, in which each team member contributes for (Sawyer, 2006).

It is important to note the role of knowledge when addressing creativity; there is a need to work with the knowledge and reshape it (Mumford et al., 2010), but as Ivcevic (2007) explains "Knowledge or skill is essential so that an individual becomes aware of what has been done, can build on it, and finally can go beyond what is known in a domain". We cannot move further in any field if we don't know what already exists, so we won't repeat it; but this idea is also very dangerous, because if while creating we cannot leave behind what we know at the present, we will never be able to move further and create new and innovative ideas. Here we have a thin line to walk and a difficult road ahead to avoid imitation and to avoid getting stuck with what already exists. It is clear that different opinions exist regarding the creative process and the scientific method, but none of us can deny that both are processes that have overlapping stages, that intertwine and present the public with outcomes that try to change the world and society in a big or in a small way.

\section{SCIENTIFIC CREATIVITY}

Creativity is required for both innovation and progress and an ability that can be enhanced by education (Schmidt, 2011). Reid and Petocz (2004) remember that creativity is not an unwavering idea; but acknowledged in different ways across domains. If we go back in time we reach a grand number of works known for their greatness and their enormous contribute to Humankind. Works such as Hamlet of Shakespeare (1825), Principia Mathematica of Newton (1846), Republic from Plato (1906), the Last Supper from Leonardo Da Vinci or Beethoven $5^{\text {th }}$ Symphony are known in the 
history of time (Simonton, 2004). Everyone has heard of these great minds and their grandiose achievements. Their creative products distinguished them from many others, but at the same time brought them together in a narrow line of genius eminence. But one of these works can clearly be distinguished from the others: the Principia Mathematica of Newton (1846). All the other can be put in an "artistic" shelf, while Newton work is clearly a scientific product. Simonton (2004) argued, while all the others works, beyond Newton's, any educated person can see or read and understand even a minimal portion of it, Newton's work is even a challenge for mathematicians. However, is undoubtedly one of the greatest works of all time. It is obvious that if we define creativity as the capability to generate new and useful ideas, Newton's work clearly falls in this definition and can in fact be considered a creative work. While this view can be staggering for some, science can and is in fact a pool of creative works. It may not develop gran paintings or sculptures or a wonderful written play, but it develops new intriguing ideas and solutions that enhance the world and move forward the fields of scientific research. As cited by Andreasen and Ramchandran (2012),

For many lay people, the word "creative" evokes images of novelists, poets, composers, and visual artists. If prompted, they would acknowledge the creativity of mathematician/physicists such as Einstein or inventors such as Thomas Edison, but there is a general tendency to assume that creativity is more associated with the arts than the sciences.

Reid and Petocz (2004) argued that creative outputs are evaluated and seen accordingly to the norms, rules and creativity definitions of the domain in which it is created; they go beyond and mention that creativity is seen differently across fields and even adopts different names such as innovation in education; entrepreneurship in business; problem solving in mathematics and performance or composition in music. Charyton and Snelbecker (2007) mentioned that the central part of creativity is problem solving; and that this process is present in the arts as is in the sciences. Baer (2012) argued that despite the need, in most domains, for a certain level of knowledge and skills for creativity, the content itself differs domain from domain. Feist (1998) said that creativity is important in all life domains, however it is particularly relevant in the arts and sciences, because although some fields can exist without creativity and still survive, arts and sciences cannot, since creativity is their baseline and essential for their survival which involves solving problems in new and original manners.

Creativity is a fundamental piece to scientific and technological ad- 
vancements (Anders and Walsh, 2009). Without the ability to think differently, to be original, to adapt and to develop new ideas, science would be static, not going beyond what is already known and society would suffer from it.

Franzoni (2010) defined creativity in science as "the attitude and capability of associating and combining scientific knowledge in an original fashion, in a way that generates new ideas, concepts, explanations or representations of phenomena." Ascheron and Kickuth (2005) stated that in the scientific world creativity is expressed through words, diagrams and mathematics that try to explain relationships, observations and phenomena; it is also openly related with helping scientists achieve new breakthroughs on how nature works, find new laws and interactions, clarify unexpected outcomes and solve problems. Creativity in science is perhaps a big leap in one's own thought, however as Hadzigeorgiou et al. (2012) said it is undeniable that science is a creative effort, the ideas that are developed through it are, simply put it, creations of our owns thoughts.

We can argue that not always creativity is at stake, maybe luck takes its part in the "gaming" of science, but "Even accidental discoveries can only be made if the scientist involved is open to the unexpected and able to pose the right questions" (Ascheron and Kickuth, 2005). Burbiel (2009) admitted that chance has had a great role in many revolutionary discoveries, such as the penicillin and that "The creative act of these researchers was to recognize the importance of unexpected findings, and what they succeed was their determination to find the reason why something had gone wrong".

$\mathrm{Hu}$ et al. (2013) stated that scientific research does need creativity to go beyond current expertise and achieve new developments in techniques and knowledge; they argued that solving problems in science entails exploration of one own expertise, imagination to explore new directions and development of new combinations of information or methodologies to achieve problems resolutions. Cruz and Smedt (2010) stated that there is some structure and constraints by previous expectations when we talk about scientific creativity; they claimed that "existing conceptual structures constrain scientists in their creative process. As a consequence, scientific creativity mostly works with small incremental steps, rather than revolutionary leaps"; however the diversity of scientific creative products that we encounter show that scientists are capable of overcoming these constraints.

All scientists and researchers are capable of using creativity in their daily works, though the extent to which creativity is used varies greatly among each person (Ascheron and Kickuth, 2005); additionally Loehle (1994) ar- 
gued that "Scientists are judged and promoted on the basis of measures of creative output (...)" which is an important reality that everyone should acknowledge.

Bringing creativity definition to science, specially the two main aspects that are regularly accepted as vital to the construct, novelty and usefulness, we may face an impasse: how can scientists and/or researchers achieve these two major points in a direct and observable measure? Scientists do not have pretty paintings to show (unless they buy them!), they don't have a beautiful new song, nor do they have a nice sculpture to be evaluated by experts. What indeed do they have? What indeed they materialize from their thinking and their experiments? The answer is quite simple: scientists and researchers showoff in their publications. If you are a scientist/researcher you know what I am talking about: those endless and boring papers (like this one!) that you need to write to let your work take its place in the world. Grosul and Feist (2014) said that "operationalization of creativity often takes the form of publication count as unit of novelty (assuming that publications make an original contribution to the literature) and citation count as a unit of usefulness or impact."

One may think, but where is creativity in a simple paper? Where do you see it? In science, it can be tricky, but it is possible. Papers and/or publications are sought in the scientific world as a way to publicly display new ideas that the researcher think will move forward his or her field of studies. If you already tried to submit a manuscript you most probably read that your work must be original (not plagiarism), but also original in its contents, that can lead to a further increase and significant improvement of the literature in the field. Bringing this element is critical, because if scientists were to publish only studies that did not have nothing new, it would literally to nothing to their field. This leads Franzoni (2010) to remark the differences between scientific productivity and scientific creativity; we may produce a lot, write lots of articles, books and present in the most important conferences internationally, but all of these may not be considered creative; creativity can be seen as Franzoni (2010) said as a subset of productivity; not all products (meaning publications) bring that "extra" element that puts the work in the creativity shelf. However, here we find again a challenge stated by Heinze et al. (2007) "Yet research judged favorably by peers is not always creative, while creative research is not always initially accepted by peers". The creativity investment theory (Sternberg et al., 1997; Sternberg, 2006) mentions this same idea, that at first sight creative ideas tend to be put aside, not accepted by the public, but that after a good "publicity" ideas 
come to be accepted by peers and the general public, who see the true value of them. In science there is this situation, where a creative idea or concept can be seen as strange or even as not forthcoming by peers, which leads to the need to "sell" the product and, hopefully, after it, it is accepted by the scientific community.

Despite its importance for science this does not mean that creativity is the sole responsible for everything that happens in the scientific world. Accordingly to Gomes (2007) "there is the myth that to the truly creative talented, their skill comes naturally, and the creative works they produce come with ease", but as Thomas Edison once said "Genius is one percent inspiration and ninety-nine percent perspiration" (Robinson, 2011); creativity is fundamental, but if the scientists, the researchers or the artists do not put their hard work on display, the ideas stay as that, as merely ideas, that do not move beyond a mind construction.

\section{REFERENCES}

Aldous, C. (2007). Creativity, problem solving and innovative science: insights from history, cognitive psychology and neuroscience. International Education Journal, 8(2), 176-186.

Anders, K., and Walsh, E. (2009). Encouraging creativity in PhD and postdoc researchers: a guide for supervisors and principal investigators. London: Imperial College London.

Andreasen, N., and Ramchandran, K. (2012). Creativity in art and science: are there two cultures? Dialogues in Clinical Neuroscience, 14(1), 49-54.

Ascheron, C., and Kickuth, A. (2005). Make your mark in science: creativity, presenting, publishing and patents, a guide for young scientists. New Jersey: John Wiley \& Sons.

Baer, J. (2012). Domain specificity and the limits of creativity theory. The Journal of Creative Behavior, 46(1), 16-29.

Basadur, M., Gelade, G., and Basadur, T. (2014). Creative problem-solving process styles, cognitive work demands, and organizational adaptability. Journal of Applied Behavioral Science, 50(1), 80-115.

Burbiel, J. (2009). Creativity in research and development environments: a practical review. Int. Journal of Business Science and Applied Management, $4(2), 35-51$.

Charyton, C., and Snelbecker, G. (2007). General, artistic and scientific creativity attributes of engineering and music students. Creativity Research Journal, 19(2-3), 213-225.

Cruz, H., and Smedt, J. (2010). Science as structures imagination. The Journal of Creative Behavior, 44(1), 37-52. 
Dacey, J. (1999). Concepts of creativity: a history. In M. Runco \& S. Pritzker (Eds.), Encyclopedia of Creativity (pp. 309-322). San Diego: Academic Press.

DeHaan, R. (2009). Teaching creativity and inventive problem solving in science. CBE - Life Sciences Education, 8, 172-181.

Feist, G. (1998). A meta-analysis of personality in scientific and artistic creativity. Personality and Social Psychology Review, 2(4), 290-309.

Franzoni, C. (2010, June). Exploratory attitude and creativity in science. Paper presented at the Summer Conference "Opening Up Innovation: Strategy, Organization and Technology” at Imperial College London Business School, London.

Garcês, S. (2011). Escala de estilos de pensar e criar - adaptação e validação à população Portuguesa (Master thesis, Madeira University, Madeira, Portugal). Retrieved from http://hdl.handle.net/10400.13/431

Garcês, S., and Pocinho, M. (2011). Escala de estilos de pensar e criar: características psicométricas. Poster presented at VIII Congresso Iberoamericano de Avaliação Psicológica/XV Conferência Internacional de Avaliação Psicológica: Formas e Contextos, Lisbon.

Garcês, S., Pocinho, M., Wechsler, S., and Jesus, S. (2014). Estilos de pensar e criar na região autónoma da madeira, Revista Iberoamericana de Diagnóstico y Evaluación Psicológica, 38(2), 55-68.

Gomes, J. (2007). What do we know about creativity? The Journal of Effective Teaching, 7(1), 31-43.

Grosul, M., and Feist, G. (2014). The creative person in science. Psychology of Aesthetics, Creativity, and the Arts, 8(1), 30-43.

Guilford, J. P. (1950). Creativity. American Psychologist, 5, 444-454.

Hadzigeorgiou, Y., Fokialis, P., and Kabouropoulou, M. (2012). Thinking about creativity in science education. Creative Education, 3(5), 603-611.

Heinze, T., Shapira, P., Senker, J., and Kuhlmann, S. (2007). Identifying creative research accomplishments: methodology and results for nanotechnology and human genetics. Scientometrics, 70(1), 125-152.

Hu, W., Wu, B., Jia, X., Yi, X, Duan, C., Meyer, W., and Kaufman, J. (2013). Increasing students' scientific creativity: the "Learn to Think" intervention program. Journal of Creative Behavior, 47(1), 3-21.

Ibérico Nogueira, S., Almeida, L., and Wechsler, S. (2012). Thinking and creating styles scale: Psychometric studies with a Portuguese sample. Poster presented at the $8^{\text {th }}$ International Test Commission Conference, Amsterdam.

Ivcevic, Z. (2007). Artistic and everyday creativity: an act-frequent approach. Journal of Creative Behavior, 41(4), 271-290.

Kirton, M. J. (1976). Adaptors and innovators: a description and measure. Journal of Applied Psychology, 61, 622-629.

Loehle, C. (1994). A Critical path analysis of scientific productivity. The Journal of Creative Behavior, 28(1), 33-47.

Mumford, M., Antes, A., Caughron, J., Connelly, S., and Beeler, C. (2010). Cross-field differences in creative problem-solving skills: a comparison of 
health, biological, and social sciences. Creativity Research Journal, 22(1), 1426.

Newton, I. (1846). Newton's Principia: The Mathematical Principles of Natural Philosophy. New York: Daniel Adee.

Nichols, A., and Stephens, A. (2013). The scientific method and the creative process: implications for the K-6 classroom. Journal for learning through the Arts, 9(1), 1-9.

Nogueira, S. I., Almeida, L., Garcês, S., Pocinho, M., and Wechsler, S. (2015). The style troika model: a structural model of the thinking and creating styles scale. The Journal of Creative Behavior. Advance online publication.

Perrine, N., and Brodersen, R. (2005). Artistic and Scientific Creative Behavior: Openness and the Mediating Role of Interests. Journal of Creative Behavior, $39,217-236$.

Plato (1906). The Republic of Plato. London: Methuen.

Reid, A., and Petocz, P. (2004). Learning domains and the process of creativity. The Australian Educational Researcher, 31, 45-62.

Robinson, A. (2011). Does Genius Follow the Ten-Year Rule? Retrieved from https://www.psychologytoday.com/blog/sudden-genius/201102/does-genius-follow-the-ten-year-rule

Sawyer, K. (2006). Explaining creativity: the science of human innovation. New York: Oxford University Press

Schmidt, A. (2011). Creativity in science: tensions between perception and practice. Creative Education, 2(5), 435-445.

Selby, E.C., Treffinger, D.J., Isaksen, S.G., and Lauer, K.J. (2004). Defining and assessing problem-solving style: design and development of new tool. The Journal of Creative Behavior, 38, 221-243.

Shakespeare, W. (1825). The Tragedy of Hamlet. London: Shakespeare Press.

Simonton, D. (2004). Creativity in science: chance, logic, genius, and zeitgeist. Cambridge: Cambridge University Press.

Sternberg, R. (2006). The nature of creativity. Creativity Research Journal, 18(1), 87-98.

Sternberg, R., O'Hara, L., and Lubart, T. (1997). Creativity as investment. California Management Review, 40(1), 8-21.

Torrance, E. P. (1965). Scientific views of creativity and factors affecting its growth. Daedalus, 94(3), 663-681.

Wallas, G. (1926). The art of thought. New York: Harcourt, Brace and Company.

Wechsler, S.M. (2006). Estilos de pensar e criar. Campinas: LAMP/PUC.

Wechsler, S.M. (2007). Estilos de pensar e criar: impacto nas áreas educacional e profissional. Psicodebate, 7, 207-218.

Wechsler, S. M. (2008). Criatividade: descobrindo e encorajando. Campinas: LAMP/IDB. 